\title{
Quality and Subjective Quantity of Sleep and its Impact on the Work Performance of Mental Health Professionals from a Public Institution in Western México
}

\author{
Ricardo Ignacio Audiffred Jaramillo*1, María del Rosario Murillo Guerrero², Alma Delia Esparza Espinoza ${ }^{2}$, \\ Francisco Márquez Sedano², Cinthya Margarita Lomelí Hernández² and José Félix Meza \\ ${ }^{1}$ Departamento de Psicología Básica, Universidad de Guadalajara, Mexico \\ ${ }^{2}$ Departamento de psicología Básica, Centro Universitario de Ciencias de la Salud (CUCS), Universidad de Guadalajara, Mexico
}

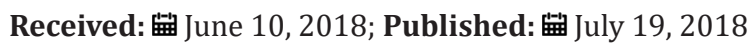

*Corresponding author: Ricardo Ignacio Audiffred Jaramillo, Clinical Research, Instituto Jalisciense de Salud Mental, Secretaría de Salud del Estado de Jalisco, Centro Universitario de Ciencias de la Salud (CUCS), Departamento de Psicología Básica, Universidad de Guadalajara. CISAME TONALÁ, calle: Prados de la Higuera\#1045 col. Prados de la Cruz. C.P. 45410. Tonalá, Jalisco, Mexico,

Tel: 013337920534, Email: rickaudiffred@hotmail.com

\begin{abstract}
Sleep alterations constitutes one of the biggest problems that affects life quality and overall performance of people, and have repercussions on low levels of work performance. The general objective of this study was to describe the relation between sleep quality and quantity and the impact on work performance of mental health professionals from Centro Asistencial San Juan de Dios in the state of Jalisco, México. The study had a descriptive, observational, cross-sectional design, which evaluated a total of 26 mental health professionals with Pittsburg Sleep Quality Index (PSQI) and an Ad hoc questionnaire about the perception over their work performence. The quality and quantity of sleep was not significantly associated with job performance $(\mathrm{p}=0,474)$. They also were not associated with errors or accidents at work $(\mathrm{p}=0,655)$. The variables sex, age, marital status, occupation (psychologist/psychiatrist), shift, and type of contract, were not associated with total sleep quality.
\end{abstract}

Keywords: Sleep Quality-Quantity; Work Performance; PSQI; Mental Health; México

Abbreviations: PSQI: Pittsburg Sleep Quality Index; CUCS: Centro Universitario de Ciencias de la Salud

\section{Introduction}

Sleep is the fundamental way to recover from our daily wear and tear [1], and it is an essential need for survival. According to [2], sleep disturbances are a major problem that affects the quality of life of a significant percentage of the population, generating mainly: fatigue, worsening of work performance and accidents, immunosuppression, memory difficulties, reduced capacity of adaptation, deficit of attention and concentration, irritability, anxiety and depression [3]. The quality of sleep is defined as the fact of "sleeping well at night and having a good functioning during the day" [4], and is associated with sleeping hours and the repercussions that they have on wakefulness [5]. Poor quality of sleep is associated with fatigue, cognitive deterioration and the greatest number of work accidents [6]. In relation to the amount of sleep, people need different amounts of sleep to feel alert. This amount varies in each person and is determined by factors of the organism, the environment and behavior [5]. On average, people should sleep for seven to eight hours (intermediate pattern), less than that period of time is considered as a short pattern of sleep ( $\leq 6$ hours), or long ( $\geq 9$ hours). The lack or excess of sufficient sleep causes a "sleep debt" that is cumulative, which directly affects the academic and work performance of the people, which causes, according to [7], a chronic fatigue, negatively affecting the productivity of people at work [8]. Also, physicians, psychologists, nurses or assistants that exceed the 48 hours of work per week recommended by the regulations of health professionals, have an altered sleep cycle. In fact, some studies conducted in Europe establish that, those health professionals who work over 70 hours have higher risks of accidents and diseases [9].

\section{Material and Methods}

The general objective of this study was to describe the relation between sleep quality and quantity and the impact on work performance of mental health professionals from Centro Asistencial San Juan de Dios in the state of Jalisco, México. The study had a descriptive, observational, cross-sectional design, which evaluated a total of 26 mental health professionals with Pittsburg Sleep Quality Index (PSQI) and an Ad hoc questionnaire about the perception over their work performence. The quality and quantity of sleep was not significantly associated with job 
performance $(\mathrm{p}=0.474)$. They also were not associated with errors or accidents at work $(\mathrm{p}=0.655)$. The variables sex, age, marital status, occupation (psychologist/psychiatrist), shift, and type of contract, were not associated with total sleep quality. This study had a descriptive, observational, cross-sectional design approved by the Research Committee of the San Juan de Dios Health Center in the State of Jalisco, Mexico.

The sample of the study was chosen by a convenience sampling from where a total of 26 Mental Health professionals were selected, under the following inclusion criteria: Psychologists and psychiatrists of both sexes of the San Juan de Dios Health Center, who have signed the informed consent and completed the Pittsburg Sleep Quality Index (PSQI) of [10], and an ad hoc semistructured self-created questionnaire, self-applicable with 37 items that evaluated the perception of Mental Health professionals about their work performance. In the non-inclusion criteria, those who did not wish to participate voluntarily in the study were considered. It was decided to exclude those who for personal reasons decided to leave the study, and those who had not completed the PSQI and the ad hoc questionnaire. The PSQI analyzed different factors of sleep quality, grouped into seven components: quality, latency, duration, efficiency and sleep disturbances, use of sleep medication and diurnal dysfunction. Each component is scored from 0 to 3 [11].

From the sum of the seven components, the total PSQI score was obtained, which ranged from 0 to 21 points (the higher the score, the worse the quality of sleep). The internal consistency with Cronbach's alpha of this test is high for the 19 items, as well as for the seven components (Cronbach's alpha of 0.81). The predictive validity data have yielded the following results: using a cut-off point of 5 (score $\geq 5$ defines bad sleepers), sensitivity was $89.6 \%$ and specificity $86.5 \%$ [12]. The analysis of the data was processed in the SPSS 20 statistical program. To analyze the possible association between the variables, the hypothesis test Chi square of Pearson and Fisher (x2) was used for categorical data and a "p $\leq .05$ " was considered significant. The participants were classified as good or bad sleepers based on the score obtained from the PSQI and the variables obtained from the ad hoc test were crossed to assess whether there was any incidence work performance.

\section{Results}

The Mental Health professionals studied were a total of 26, of whom 14 were men (54\%) and 12 women (46\%). The mean age was $31 \pm 8$ years (24-61 years). $61.5 \%$ were single, $23.1 \%$ married, $3.8 \%$ were separated and $11.5 \%$ were living together. Of the total evaluated 7 were psychologists (27\%) and 19 psychiatrists (73\%), of which 21 belonged to the morning shift (80\%), 1 to the evening shift (4\%) and 2 to the night shift and accumulated day respectively (16\%); 9 had a temporary contract (34\%) and 17 were basic workers (84\%) with an average seniority of $4 \pm 6$ years (1-26 years). $80.7 \%$ of the sample slept 6 hours or less daily, with an average of 6 \pm .977 hours (4-8 hours). $26.8 \%$ of the total, perceived that they had a sufficient night's sleep ( $\geq 7$ hours), and $73.1 \%$ (21 subjects) an insufficient sleep ( $\leq 6$ hours). The association between sufficiency of sleep and being good or bad sleepers (Total PSQI) was next to be significant ( $\mathrm{x} 2=.344, \mathrm{p}=.06$ ). The $61.5 \%$ of the sample reported not being able to lift easily in the morning and $53.8 \%$ indicated that they wake up feeling tired. 53.8\% felt occasionally sleepy during their workday and $92 \%$ perceived that the few hours of rest had a negative influence on their work performance, although only $42.3 \%$ (11 people) reported having made some mistake in their work.

The work because of fatigue and of these, 53.8\% (6 people) mentioned committing them occasionally ( 2 to 3 times a month). However, no association was found between the perception of sleep sufficiency and the errors made at work $(p=0.655)$ or work performance $(p=0.474)$. The consumption of natural substances (coffee or tea) and the strategy of restful sleep were two of the most frequent activities in the sample to stay active during the day. 50\% used substances to feel alert during the day, three or more times a week. The most used were coffee, and tea. $92 \%$ had restful dreams during the day. The average number of minutes of rest was 54.2 \pm 39 minutes (0-120 minutes). Restful sleep was not associated with the improvement of work performance $(\mathrm{p}=.151)$ or with errors at work ( $\mathrm{p}=.492)$. Only $38.5 \%$ reported complications to fall asleep. The average time to sleep after lying down was $23.9 \pm 22.02$ minutes (0-90 minutes). As for the PSQI, the average total score was $6.96 \pm 2.93$ (2-13 points). The subjective quality of sleep was quite good in $7.7 \%$ of health professionals, good in $65.4 \%$, poor in $23.1 \%$ and very poor in $3.8 \%$. Regarding sleep latency, $57.6 \%$ had a good latency ( $\leq 15$ minutes), $23 \%$ had a slight alteration (16-30 minutes), $15.3 \%$ had a bad latency (31-60 minutes) and 3.8\% a very bad latency ( $\geq 60$ minutes).

$73 \%$ reported having this alteration at least once a week. No association was found between the difficulty of falling asleep and the mistakes made at work $(\mathrm{p}=0.588)$. In relation to the duration of sleep, $7.6 \%$ had a good duration ( $\geq 7$ hours), $57.6 \%$ a slight alteration (7-6 hours), 34.6\% a bad duration (5-6 hours). hours). In terms of sleep efficiency, the average was 6 hours. There was no significant alteration of sleep in the sample since the most prevalent responses were: less than once a week and no time a month. The $80.7 \%$ of the sample scored in the PSQI as bad sleepers, without differences between sex, marital status, profession, working hours, and type of contract. The total results on good and bad sleepers that the PSQI showed were not significantly associated with the variable "perception of work performance" ( $p=.654)$.

\section{Discussion}

The short sleep pattern ( $\leq 6$ hours) of the majority of the sample coincides with the perception of sleep insufficiency, a relationship that was close to being significant ( $\mathrm{x} 2=.344, \mathrm{p}=.06$ ). This explains that there is awareness of the bad sleep habits that prevail in the daily occurrence of the participants. Some studies, such as that of have correlated poor sleep quality with a higher incidence of accidents cited in [13], also point out in their meta-analysis research on 27 observational studies, that the poor quality of sleep and a short time of sleep among other variables, increase the risk of work accidents up to $62 \%$. However, other studies such as cited in state that there are no significant differences between the quality of sleep and the risk of having a work accident. In the present 
study, although $92 \%$ of participants thought that the few hours of rest have a negative influence on their work performance, but only $42.3 \%$ committed errors at work due to fatigue. Though, no association was found between the perception of sleep sufficiency and the errors made in work or work performance $(p=0.655)$.

Therefore, these results coincide more with those of on the other hand, the high number of bad sleepers described in this study exceeds the data found by [5] in 675 medical students where $64.5 \%$ on average were classified as bad sleepers This states the vulnerability to sleep disorders suffered by psychologists and psychiatrists. However, the mean total score was $6.96 \pm 2.93$ (213 points). Data lower than the index of subjects participating in a study with rotating night shift workers who obtained a global PSQI sleep index of 8.09 [7] which are described in the medical literature like the worst sleepers (who work on night shifts and rotating schedules). Regard to the bad sleepers in the sample, no differences were found in the variables: sex, marital status, profession, working day and type of contract; a situation coinciding with that reported by [13], a study in which variables did not represent a significant incidence. The only variable in which it was deferred was that of sex, in which the authors mention that women score higher on the full scale than in comparison with men. In conclusion, 80.7\% (21 people) were classified as bad sleepers. The quality and quantity of sleep was not significantly associated with work performance ( $p$ $=0.474)$.

The perception of these variables was also not associated with errors or accidents at work $(p=0.655)$. The variables sex, age, marital status, profession (psychologist / psychiatrist), shift, and type of contract were not associated with the quality of the total sleep. The population of mental health professionals may have a high prevalence of sleep disturbances in the quality and perceived amount of sleep, as shown by the data obtained in this study. However, there is not enough research to account for this phenomenon. The majority of studies that are available in the medical literature describe what happens with medical students, nurses and doctors of other specialties who rotate shifts and make superior guards at 48 hours. One of the perspectives on this topic is to carry out more studies with other types of designs which correlate these variables with others that were not considered in the present due to time constraints, the scope of the design and the small number of participants in the design. the sample that was available.

\section{Acknowledgment}

To the medical director of the San Juan de Dios Healthcare Center, Dr. Hugo D. Castellanos Martín and to Dr. Palmira Orozco
Manríquez, Head of Education, for all the support and collaboration for this study to be carried out; and to all the staff of that institution that collaborated in the present work. We also thank the Head of the Department of Basic Psychology, Mtro. Francisco José Gutiérrez Rodríguez of the University Center of Health Sciences of the University of Guadalajara, for his valuable support in the logistics for carrying out this research.

\section{References}

1. Miró E, Martinez P, Sánchez AI, Rodríguez J (2007) Relación entre el burnout o "síndrome de quemarse en el trabajo", la tensión laboral y las características del sueño. Psicothema 19(3): 388-394.

2. Pineda JE, Ortiz EE, Ayala F, Domínguez B (2013) Construcción y validación de una prueba mexicana para evaluar el sueño. Resultados preliminares. Psicología y Salud 23(1): 131-139.

3. Marín A Hernán A, Franco AF, Vinaccia A, Tobón S, Sandín B (2008) Trastornos del sueño, salud y calidad de vida: una perspectiva desde la medicina comportamental del sueño. Suma psicológica 15(1): 217-240.

4. Borquez P (2011) Calidad de sueño, somnolencia diurna y salud autopercibida en estudiantes universitarios. Asunción Paraguay 8(1): 80-91.

5. Barrenechea-Loo MB, Gómez-Zeballos C, Huaira-Peña AJ, PregúnteguiLoayza I, Aguirre-Gonzales M, et al. (2010) Calidad de sueño y excesiva somnolencia diurna en estudiantes del tercer y cuarto año de medicina CIMEL 15(2): 54-58.

6. Rey de Castro J (2003) Accidentes de tránsito en carreteras e hipersomnia durante la conducción. ¿Es frecuente en nuestro medio? La evidencia periodística. Rev Med Hered 14(2): 69-73.

7. Sierra JC, Delgado-Domínguez C, Carretero-Dios H (2009) Influencia de la calidad de sueño sobre variables psicopatológicas: un análisis comparativo entre trabajadores sometidos a turnos y trabajadores con horario normal. Revista Latinoamericana de Psicología 41(1): 121-130.

8. Vera A, Contreras GR (2008) Importancia de los trastornos del sueño como causa de fatiga en trabajadores mineros en Chile. Ciencia \& Trabajo 10(29): 82-84.

9. Bocanegra JC (2002) Sobrecarga laboral en los profesionales de salud y su relación con la seguridad del paciente. Revista Médico Legal 18(1): 6-13.

10. Buysse DJ, Reynolds CF, Monk TH, Berman SR, Kupfer DJ (1989) The Pittsburgh Sleep Quality Index: A new instrument for psychiatric practice and research. Psychiatry Research 28(2): 193-213.

11. Parra A (2014) Diferencias individuales en la frecuencia del recuerdo de sueños exóticos. Suma Psicológica 21(1): 63-69.

12. Lomelí HA, Pérez-Olmos I, Talero-Gutiérrez C, Moreno CB, GonzálezReyes R, et al. (2008) Escalas y cuestionarios para evaluar el sueño: una revisión. Actas Esp Psiquiatr 36(1): 50-59.

13. Mañas CM, López MP (2016) Análisis de la calidad de sueño en una muestra de trabajadores del sector público. Revista Enfermería del Trabajo 6(1): 4-11. 


\section{ISSN: 2574-1241}

DOI: $10.26717 / B J S T R .2018 .07 .001443$

Ricardo Ignacio Audiffred Jaramillo. Biomed J Sci \& Tech Res

(c) (i) This work is licensed under Creative

Submission Link: https://biomedres.us/submit-manuscript.php

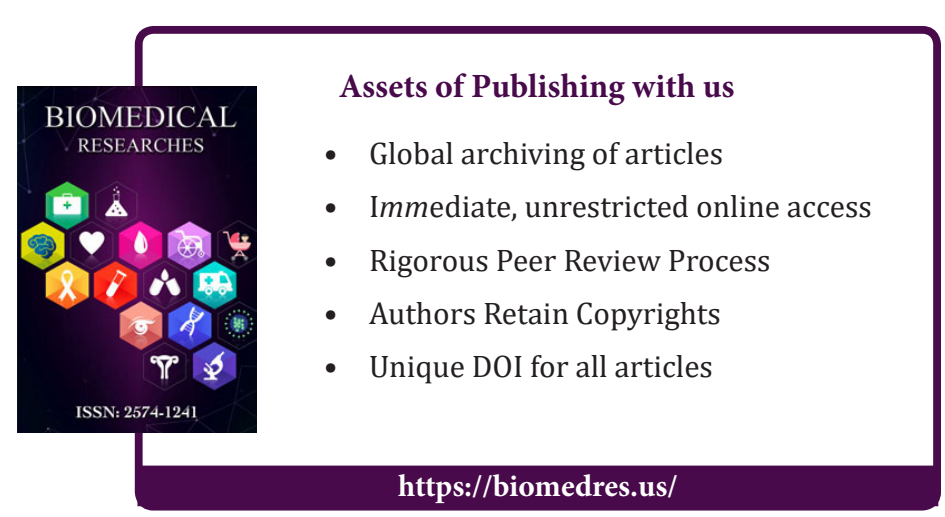

